\title{
FIGADO NO METABOLISMO DE PROTEINAS (*)
}

\author{
Prof. F. A. de MOURA CAMPoS
}

Encarado sob o aspecto chimico-hiologico, ou analysado na sua feição physio-pathologica o assumpto desta palestra é demasiadamente longo. Dai a necessidade de cerceal-o. Resolvemos, pois, tecer algumas considerações sobre a funç̧ão uropoietica e sobre a formação de um deposito de proteinas no figado. Lá focalizaremos, de preferencia, os trabalhos de KREBS e HENSELEIT (1), de um lado, em torno do cyclo da ureogenese e os de BOLLMAN, MANN e MAGATH (2), indicando os effeitos da extirpação dos rins e 'do figado sobre o metabolismo das proteinas. Aqui traremos a palavra do Departamento de Physiologia da nossa Faculdade.

\section{FUNCC.ÃO UROPOIETICA}

Se ROULE mostrou pela primeira vez a presença da uréa na urina, em 1773, dando a esse corpo um papel importante no metabolismo nitrogenado; se PRÉVOST e DUMAS, em 1823, registraram a sua presença no sangue, somente em 1882 a intervenção do figado na uropoiese ficou bem documentada com os trabalhos de SCHROEDER (3), que dosando a taxa de uréa do sangue da veia porta e a do sangue das supra-hepaticas e calculando a differença poz em relevo a intervenção das cellulas hepaticas no metabolismo azotado. Os amino-acidos, que resultam da demolição do edificio proteico, pela intervenção dos fermentos proteolyticos do apparelho digestivo, chegam ao figado, onde podem soffrer um processo de desaminação. $\mathrm{O}$ grupo aminico, $\mathrm{AzH}_{2}$, forma a ammonea, que se liga a acidos organicos e mineraes, formados no proprio organismo, ou nelle introduzidos com a alimentação. Surgem os saes ammoniacaes. Quando estes provem de acidos organicos, fracos, de baixo coefficiente de dissociação ionica, como o lactico, benzoico, etc., podem contribuir para a formação da uréa. Pela lei da acção das massas o acido carbonico os modifica, transformando-os, por dupla deshydratação, em carbonato, carbamato de ammonio e uréa. Já outro tanto não succede quando se originam de acidos mineraes, fortes, de alto coefficiente de dissociação ionica. Sob a forma de saes ammoniacaes os rins os eliminam.

(*) Conferencia realizada no Departamento Scientifico do Centro Academico Oswaldo Cruz, em 16 de Setembro de 1939. 
$\mathrm{Na}$ ammoniogenese, primeira etapa do catabolismo endogeno das proteinas, cooperam efficazmente os rins. Acreditam, mesmo, NASH e BENEDICT em uma intervenção notavel destes orgãos.

A formação da uréa opera-se, tambem, por outros mechanismos. São bem conhecidos os trabalhos de WOHLLER, FEARON e MONTGOMERY, indicando que a oxydação da alanina e da glycina pelo peroxydo de hydrogenio, em meio alcalino, permitte a produção de uréa e acido cyanico. A creatina, que é o acido methylguanidino-acetico, pode, por hydratação, produzir uréa e sarcosina (methyl-glycina). A arginina, operada, pela arginase, fermento soluvel encontrado no figado, produz ornithina e uréa.

Acreditavam, porém, autores antigos que diariamente a taxa de uréa produzida pelos tres ultimos methodos citados não ultrapassava um decimo da somma elaborada na economia animal.

Considerando, todavia, os trabalhos de KREBS e HENSELEIT essa concepção tende a se modificar. Estes autores descreveram no tecido renal, e, depois no tecido hepatico, um fermento - a desamino-oxydase, capaz de agir por desaminação oxydativa sobre monopeptidios, produzindo ammoniaco. Este, em presença de $\mathrm{CO}_{2}$, póde agir sobre a ornithina, formada no desdobramento da arginina, produzindo citrulina, amino-acido com nucleo ureico, e agua. Uma nova mollecula de ammoniaco transforma por deshydrataçãa a citrullina e arginina. Dahi um verdadeiro cyclo de ureogenese. E' interessante registar o conjunto dessas reacções, que lembram um processo reversivel em tão delicado mechanismo biologico. Merecem reparo essas transformações, que se operam com gasto minimo de energia, economicamente, transformando em materia prima o que poderia ser considerado como residuo.

A formação de uréa traduz a actividade das cellulas hepaticas. Os rins trabalham no preparo do ammoniaco e na eliminação da uréa. Os trabalhos de BOLLMAN, MANN e MAGATH, da Mayo Foundation, são notaveis pelo criterio com que foram realisados e pelos profundos ensinamentos que trouxeram. Operando animaes de todos os grupos de vertebrados chegaram a conclusões interessantes. Conseguiram em muitos delles retardar a manifestação do choque hypoglycemico, pela administração systematica de sôro glycosado e, assim, estudaram com mais detalhes as mutações biochimicas do sangue e da urina dos cães hepatectomisados e nephrectomisados. Mediram a resistencia dos animaes a varios typos de operação, como segue:

Resistencia em horas
A - Extirpação do figado $\ldots \ldots \ldots \ldots \ldots \ldots \ldots$
$6-24$

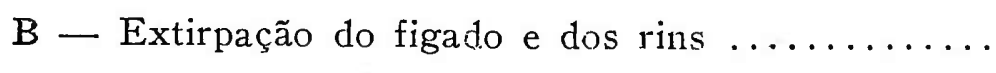
C - Extirpação dos rins e 5 a 24 horas depois extirpação do figado $\ldots \ldots \ldots \ldots \ldots \ldots \ldots$.
$5-12$
$3-8$ 
Vê-se que a extirpação do figado é incompativel com a vida, que a resistencia dos animaes decresce com a remoção dos rins e principalmente quando esta operação precede aquella de algumas horas.

Quando o figado é removido isoladamente nota-se queda progressiva da uréa no sangue e na urina e augmento dos amino-acidos no sangue. Bem comprehensiveis esses factos. Sendo o figado o orgam formador da uréa, os rins os orgãos eliminadores e o sangue o meio intermediario, a extirpação daquelle e a conservação destes devem acarretar hypoazotemia e hypoazoturia progressivas com hyperaminoacidemia.

Sendo os rins removidos simultaneamente com o figado a aminoacidemia cresce mais rapida $e_{i}$ intensamente e a azotemia se conserva constante. Aquelle facto decorre da exclusão do tecido renal, centro notavel de ammoneogenese. Este é o fruto da interrupção do mechanismo de eliminação da uréa. Por vezes ha ligeira reducção da azotemia, explicavel pela eliminação de uréa, por intermedio da saliva e dos vomitos.

No terceiro typo de intervenção ha hyperazotemia no inicio e manutenção da uréa em taxa alta após extirpação do figado. A. aminoacidemia cresce em duas opportunidades; quando os rins são extirpados e após a remoção do figado.

A analyse das variações biochimicas referidas indicam bem que os rins participam activamente na ammoniogenese e na eliminação da uréa. A formação desta, a partir de acidos aminados é, porém, funcção das callulas hepaticas.

\section{DEPOSITOS DE PROTEINAS NO FIGADO}

Este assumpto é magistralmente discutido por CANNON (4), em seu livro "The wisdom of the body". O organismo animal necessita de taxas relativamente pequenas de proteinas. Estas, todavia, devem ser fornecidas diariamente e de boa qualidade. Assim entendemos as que encerram em proporções recommendaveis os aminoacidos indispensaveis. Desconhecendo o mechanismo de synthese da lysina, tryptophano, cystina e tyrosina o organismo somente conta com o seu transporte pela alimentação.

Analysaremos em primeiro lugar, se as proteinas são depositadas normalmente no corpo. Veremos, depois, que no figado ellas podem ser guardadas sob uma forma labil. Finalmente cuidaremos do seu processo de mobilisação.

$\mathrm{O}$ primeiro quesito é respondido positivamente pelos argumentos de THOMAS (5) e de BOOTHBY (6).

Argumento de Thomas: Alimentou-se, de inicio, este pesquisador com uma dieta rica em proteinas. Adoptou, depois, durante 8 dias uma ração aproteica, constituida exclusivamente 
de hydratos de carbonio. Calculou o azoto total da urina diariamente. Notou a suı reducção progressiva, até estabilisação em 2,2 grs. por dia. Esta seria a taxa minima, inevitavel, compativel com a manifestação dos actos vitaes. Dahi o calculo:

Taxa minina de $\mathrm{N}$ por dia $\ldots . . . \ldots \ldots \ldots$.

Taxa minima de $\mathrm{N}$ para 8 dias de ração

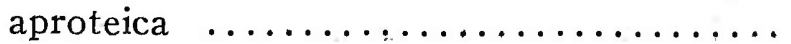

Taxa de $\mathrm{N}$ total em 8 dias $\ldots . . \ldots \ldots \ldots . .$.

Taxa de $\mathrm{N}$ proveniente de proteinas armazenadas sob a forma de reserva ..........

Taxa de proteinas sob reserva utilisadas em

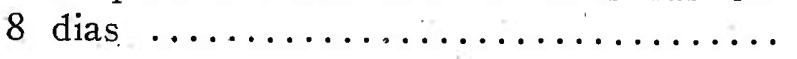

Taxa de proteinas de tecidos desintegrados em 8 dias $\ldots \ldots \ldots \ldots \ldots \ldots \ldots \ldots$.

2,2 grs.

$$
2,2 \times 8=\begin{array}{r}
17,6 \quad " \\
66,0
\end{array}
$$

$60,0-17,6=48,4 \quad "$

$48,4 \times 6,25=302,580$

$17,6 \times 6,25=110,0 \quad \cdots$

Argumento de Boothby: - Forneceu-lhe uma experiencia feita com o jejuador Levanzin e teve como base a eliminação de creatinina pela urina. Esse corpo azotado parece traduzir pela sua taxa a desintegração dos tecidos para a manutenção do rythmo vital. E' independente da proporção de proteinas na dieta. Viejamos o raciocinio de BOOTHY:

Taxa de creatinina eliminada durante o jejum de 31 dias ..........................

Taxa de $\mathrm{N}$ correspondete á creatinina eliminada Perda total de $\mathrm{N}$.......................

Taxa de $N$ proveniente de proteinas sob forma de reserva ....................

Taxa de proteinas sob reserva, utilisadas em

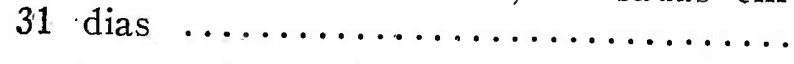

Taxa de proteinas de tecidos desintegrados durante 31 dias $. . . \ldots \ldots \ldots . . . . . . . . .$.

$$
\begin{array}{r}
10,7 \text { grs } \\
62,0 " \\
277,0 " \\
277-62=215,0 " \\
215 \times 6,25=1343,0 " \\
62 \times 6,25=387,5 \quad
\end{array}
$$

Ao segundo quesito responderemos com as observações de AFANASSIEV, PFLÜGER, SEITZ, TICHMENEFF, LUCK, WHIPPLE eas nossas, em collaboração com CAVALCANTI e PAULA SANTOS.

Experiencia de Afanassiev - Em 1883 AFANASSIEV: (7) já affirmava a existencia no figảdo de proteinas, sob forma labil, em deposito facilmente mobilisavel pelo organismo nos momentos opportunos. Alimentando cães co muma dieta rica em proteinas notára augmento da consistencia do figado e do volume das suas cellulas, nas quaes surgiam granulos, que reacções histo-chimicas revelaram de natureza proteica. Seria esta fracção diversa 
da de natureza mais estavel, que participa na estructura dos orgãos.

Experiencia de Pflúger - Submettendo animaes a uma dieta rica em proteinas, PFLÜGER (8) verificou a formação no figado de um deposito destas substancias, utilisando a potassa, a quente, na sua desintegração.

Experiencia de Seitz - Mais significativos foram os dados co1hidos por SEITZ (9). Este determinou a relaçãor $\frac{N^{\top} \text { do figado }}{N^{\top} \text { do resto do corpo }}$ em animais inanidos e em outros alimentados com carne de vitella. Achou-a duplicada ou triplicada, elevação somente comprehensivel e possivel pelo augmento do nitrogenio hepatico. $E$ foi o que succedeu.

Experiencia de Tichmeneff (10) - Ratos jovens foran. deixados em jejum, durante 2 dias. Sacrificados foi procedida a dosagem de proteinas do figado. $O$ outro lote foi bem alinientado com uma dieta rica em proteinas e sacrificado postrriormente. Nos animaes deste ultimo grupo a taxa de proteinas do figado augmentou de 53 a $78 \%$.

Experiencia de Luck - LUCK (11) avaliou em ratos submettidos a dietas pobre ou rica em proteinas as taxas de substancias proteicas do figado, musculos esqueleticos, rim e intestino. As taxas do figado e do intestino oscillaram com os typos de ração. Conservaram-se mais ou menos constantes as dos musculos e rim.

Experiencia de Whipple e collaboradores (12) - No sangue as proteinas do plasma participam da sua estructura. Não têm funcção alimentar. Cooperam na manutenção da pressão osmotica do sangue. Podem ser removidos em grande taxa, retirando-se sangue, suspendendo os elementos figurados em solução physiologica e injectando-os de novo. Foi assim, possivel reduzir, no cão, a taxa de proteinas do plasma de 6 a 2\%. Em 24 horas, todavia, a sua restauração se realisava na proporção de $40 \%$. O mesmo não succedia quando o animal era portador da fistula de ECK, que exclue o figado da circulação. De outro lado era lenta e difficil a restauração quando intoxicado o figado pelo phosphoro.

Experiencias pessoaes - Em uma primeira serie de experiencias verificámos, com CAVALCANTI (13), que ratos jovens, alimentados com uma dieta onde a fonte de proteina era a legumina da ervilha, na taxa de 4,9\%, não cresciam. $O$ theor de 
proteinas do figado reduzira-se, em media, a $15,23 \%$, ao passo que em animaes normaes, da mesma idade era de $23,11 \%$. A taxa de proteinas dos musculos esqueleticos fôra de $21,60 \%$, muito proxima á de $21,17 \%$ obtida nos mesmos tecidos para os animaes testemunhas.

Em uma outra opportunidade, com CAVALCANTI e PAULA SANTOS (14) empregämos rações com 12,3 e 17,22\% de legumina. Embora ainda sub-normaes as curvas de crescimento os animaes reagiram em condições melhores que os da primeira serie. Os dados obtidos estão indicados no quadro abaixo :

\section{DIETAS}

Com $4,9 \%$ de legumina $\ldots \ldots \ldots \ldots \ldots \ldots$

Com 12,30 a $17,22 \%$ de legumina ..............

Completa, com caseina, lactalbumina e gluteina

$\begin{array}{cc}\begin{array}{c}\text { Proteina do } \\ \text { figado }\end{array} & \begin{array}{c}\text { Proteinas dos } \\ \text { musculos }\end{array} \\ \text { grs. } \% & \text { grs. } \% \\ 15,23 & 21,60 \\ 19,33 & 23,79 \\ 23,11 & 21,17\end{array}$

$E^{\prime}$ de interesse notar que emquanto nos musculos esqueleticos as taxas de proteina foram muito proximas nas tres condições experimentaes, outro tanto não succedeu com os dados obtidos para as proteinas do figado. Aqui as taxas foram muito diversas, elevando-se progressivamente á miedida que a dieta usada mais se approximava da ração completa. Parallelamente, com o augmento das proteinas hepaticas foi observada uma melhoria na curva de crescimento. Dahi admittirmos (15) a existencia de uma relação estreita entre o desenvolvimento dos animaes jorvens e a formação de um deposito de proteinas no figado. Esse deposito seria de proteinas labeis, facilmente mobilisaveis pelo organismo em condições de alimentação hypoazotada. Dietas pobres em proteinas não podem fornecer material proteico para um armazenamento hepatico. Esta seria uma funcção secundaria no tempo, sendo primaria a de restauração das proteinas gastas no catabolismo diario. Em prol da hypothese que defendemos surgiu o seguinte facto, muito demonstrativo: o rato 882 , alimentado com uma ração contendo 17,22 de legumina da ervilha e manifestando crescimento sub-normal, passou a receber cystina a $2 \%$. Após um mez, com augmento nitido de peso, foi sacrificado, revellando o figado $24,50 \%$ de proteinas. A deficiencia da legumina, que é em cystina, segundo os estudos de THOMAS (16), OSBORNE e MENDEL (17) e OSBORNE e WEYL (18), foi compensada, a ponto de permittir o crescimento do rato e a formação de um optimo deposito de proteinas no figado.

Ao terceiro quesito responderemos, parcialmente, com as observações de CANNON (19), de RIECKER e WINTERS (20). Aquelle mostrou que o sangue colhido em animaes durante a emoção tem ređuzido o seu tempo de coagulação. No mesmo sentido agiria a adrenalina injectada. Esse encurtamento do tempo de coagulação é devido, possivelmente, ao enriquecimento do sangue em 
fibrinogenio, funcção que o figado pode desempenhar. RIECKER e WINTERS obtiveram um augmento de $36,3 \%$ na taxa de fibrina quando injectaram adrenalina. Ao mesmo tempo reduziu-se de $60 \%$ o tempo de coagulaçãa.

\section{BIBLIOGRAFIÁ}

1) KREBS e HANSELEIT - Citados por CRISTOL, Précis de Chimie Biologique Médicale, 1935, p. 522.

2) BOLLMAN, MANN e MAGATH - Am. J. of. Physiol., 1926, $78,259$.

3) SCHROEDER - Citado por MITCHELL, H. H. e HAMILTON, T. S. The biochemistry of the aminoacids, 1929, 282.

4) CANNON, W. B. - The wistom of the body, 1932, 122.

5) THOMAS - Arch. f. Physiol., 1910, 249.

6) BOOTHBY, SANDIFORD e SLOSSE - Ergebn d. Physiol., 1925, 24, 733.

7) AFANASSIEV - Pflüger's Arch., 1883, 30, 385.

8) PFLƯGER, E. - Arch. ges. Physiol., 1903; 96, 1.

9) SEITZ, W. - Arch. ges. Physiol., 1906, 111, 309.

10) TICHMENEFF - Bioch. Zeits. 1914, 59, 326.

11) LUCK, J. M. - J. of Biol. Chem., 1937, 115, 491.

12) WHIPPLE, SMITH e BELT - Am. J. of Physiol., 1920, 52, 72.

13) MOURA CAMPOS, F. A. e CAVALCANTI, T. A. A. - O Hospital, 1938, 13, n. $2,247$.

14) MOURA CAMPOS, F. A. CAVALCANTI, T. A. A. e PAULA SANTOS, O. - Folia Clinica et Biol., 1938, n. ${ }^{\circ}$ 3, 97.

15) MOURA CAMPOS, F. A.- - Arch. Scienze Biologiche, 1938, 24, n. ${ }^{\circ} 6,500$.

16) THOMAS, P. - Manuel de Biochimie, 1936.

17) MENDEL, L. B. - J. of. Am. Med. Assoc., 1915, 64, n. ${ }^{\circ} 19,1539$.

18) OSBORNE, T. B. e WEYL, - Am. J. of Physiol., 1908, 22, 362.

19) CANNON, W. B. - Bodily changes in hunger pain and rage, 1924.

20) RIECKER e WINTERS - Proc. Soc. Exp. Biol. \& Med. 1931, 28, 671 . 